\section{Wood in housing}

The main concern of the Consultation was clearly to improve the availability of housing, particularly for lower-income peoples of all countries whether highly industrialized or developing. It was recognized that this could be best done by making economic use of all housing materials, both wood and non-wood, which could well help to provide additional employment in many countries. It was very evident, however, that in many countries with adequate forest resources or the opportunity to develop wood supplies, this material was not used to its best advantage. Hence, much of the work of the Consultation was concerned with how to take fuller and more effective advantage of the opportunities to use the many and diverse wood building materials.

With little more than half of one percent of the world's growing stock of timber now being used annually, it is evident that those countries with the necessary facilities for procurement are likely to have little difficulty in securing sufficient wood materials to cover their foreseeable housing requirements, but there are some countries with pressing housing needs possessing considerable forest resources not fully exploited who will find it necessary to make greater use of their forest potential to improve their housing situations and at the same time benefit their national economies.

Unhappily, however, there are regions, especially in Asia and the Far East, where more than forty percent of the world's population will be able to use for housing barely five percent of the world's supply of wood materials. Although in some cases new plantations could help future needs and some importation could be developed, it seems clear that some of these areas may have to look to the use of materials other than wood to provide housing needs.

The renewability of the forest resource, and thus its continuing availability as a source of products for housing, together with the relatively minor impact on the environment suggests that wood is a highly desirable source of building materials. In many instances, market demands or local prejudices result in only limited exploitation of certain species; these may be an important source of housing materials. Their successful use in solving pressing housing problems, however, will depend in large part on their correct use, seasoning before installation, preservative treatment and the like. Improper use, and the failures which will inevitably result, can only militate against the use of wood and thus result in the loss of a highly desirable source of building materials. This suggests strongly that developing countries should work toward an increasing level of technology, a process in which developed countries can play a vital role.
Extracts from the closing address by D. R. REDMOND, General Chairman, to the World Consultation on the Use of Wood in Housing. This UN-sporssored meeting, attended by representatives from 60 countries, was held in Vancouver, B.C., July 5-16, 1971 . The Consultation Report will be published towards the end of the year.

Wood gives excellent performance as a structural material when used in a proper fashion. Problems arise primarily from its misuse. All too often, architects and engineers are not competent to design with wood, especially with respect to the needs of the country and the desires of its people. Fire hazards and preservation requirements are two problem areas. The Consultation expressed the conviction that wood, when properly treated and utilized, does not constitute a fire hazard to occupants in excess of that of other construction materials as conventionally used, and that construction practices and protection methods are available to ensure safety of occupants. Deterioration of wood in use can be minimized by the use of durable resistant species, proper preservation, and correct construction practices. The delegates did express a need, however, for chemical treatments that were easy to use, inexpensive, and which were applicable to treatment of naturally impermeable species and incompletely dried timber.

The introduction of sound and yet simple designs could be facilitated through the establishment of a central, international clearing house for technical information, with particular reference to design aids for timber engineering and building practice. The flexibility of wood in relation to design, and the methods of production permit the adoption of a whole range of techniques appropriate to the technological level and market conditions in a given country, ranging from on-site construction to complete prefabrication. The road to industrialization will, however, require the attainment of the following consecutive thresholds; standardization of products of sawn wood and wood-based panels; development of mass production of joinery and structural components; production of panels for walls, etc.; and finally, production of whole house systems.

Concerning the use of wood in housing in developing countries, it was concluded that use would decline unless new policies were adopted and measures taken. It was recommended that a number of steps be taken to stimulate the use of wood, including the adoption of measures to modernize the sawmilling industry, the preparation of grading rules, and the development of technologies appropriate to local conditions.

A major recommendation of the Consultation was to establish under a UN agency a central unit to deal specifically with problems relating to the use of wood in housing. Its functions would be to provide communication, solve specific problems, secure liaison and co-operation and to support as advisable development programs in other institutions. 